\title{
Self-presentation Strategy of WeChat Users with Motives Impact on the Formation of Online Social Capital
}

\author{
Haihui Guo* \\ Panyapiwat Institute of Management \\ Nonthaburi, Thailand \\ 171053221@qq.com
}

\author{
Yunlong Duan \\ Panyapiwat Institute of Management \\ Nonthaburi, Thailand \\ 827987867@qq.com
}

\begin{abstract}
WeChat is a social networking platform. WeChat users create the content online to present themselves online, called self-presentation strategy, to build a personal network identity. This identity has the form of capital -- the social capital. If the WeChat users take full account of the dimensions of the relationship maintenance and relationship initiation, the selfpresentation of individual online social capital will be shaped more effective, and this effect will be positively magnified. The study proved the moderator role of motive of WeChat usage in effectively adjustment the formation of WeChat users' online social capital shaped by self-presentation.
\end{abstract}

\section{Keywords—self-presentation; WeChat; social capital; motive}

\section{INTRODUCTION}

In the past few years, instant messaging as a social media tool offering real-time text over the internet has gained popularity among Chinese users. The form of social interaction is moving online, and online social networks are becoming an important source of information and social capital. As a social network platform, WeChat uses "smart connector" strategy to expand its information distribution, interactive sharing and content production channels for various types of service providers and the audiences as well. WeChat offers a service platform for third-party developers to provide a full-spectrum services development and promotion of space. Literally, while Facebook and WhatsApp measure growth by the number of daily and monthly active users on their networks, WeChat pays more attentions to how relevant and central WeChat is in addressing the daily, even hourly needs of its users. Beyond focusing on forming a mobile lifestyle, the goal of WeChat is to address all aspects of its users' lives, including non-social ones. Actually, WeChat is a personal portal to the world. To date WeChat has become the first and foremost important App on mobile phones of about $4 / 5$ of total Chinese population [6].

Day after day, WeChat users deliver contents, post opinions, describe ideas, show the voice, and offer their concerns and helps, to impress their image upon their networked ties. The image shows the spirit, culture, education and other characteristics. Simultaneously, a user built their own online social identity on the network, thus forming their certain degree of recognition of social capital.

Tactical self-presentation can promote the closeness between people and play a pivotal role in the development of interpersonal relationships. People have the need to show their true self through self-disclosure to establish relationships with others [12]. The interactive parties can not only understand each other, but also define the type of relationship, and will influence the individual's assessment of the self and the identity of the individual, based on the degree of reciprocity, including quantity, type, privacy, etc..

Therefore, in the process of self-presentation of WeChat users, if the motives of the users are taken into consideration, the formation of personal online social capital of the WeChat users can be much more effective. The paper is about to explore the mechanism of the moderating role of motives of WeChat users.

\section{LITERATURE REVIEW}

\section{A. Motives to WeChat usage}

The use of tools for social relationships can be divided into two categories: relationship maintenance and relationship initiation. The main function of maintaining a relationship is to maintain a necessary relationship with friends, such as commitment, love, satisfaction, etc. [17]. Relational maintenance can be applied to real life, but also to the networked social platform scenario. The platform users can update the current profile description, comment on friends, praise, post an image, and create community and other acts to maintain or repair existing relationships with friends

Motives determine the intention of users of internet to engage in Apps by gratifying certain needs they hope to cherish WeChat platform has social affordance with the performance of a mixed online and offline social relations. Many researches and studies shows that building a friend relationship, maintaining a friend's relationship, and contacting others is the basic need for mankind [1][16]. Some of the research on social networking sites (SNS) suggest that the main motivation for users to use the SNS site is to keep existing relationships with friends and create new relationships [10][13]. Thus, relationship maintenance and relationship initiation can be considered as the two important motive dimensions for WeChat users.

As the advance of WeChat is of still relatively short period, the WeChat academic research literature is relatively few. The

\footnotetext{
* Corresponding author
} 
literature on its counterpart is comparable. The paper takes the similar research in Facebook to recap the progress. DeAndrea \& Walther (2011) [8] pointed out that Facebook serves as a tool for college students to maintain and strengthen existing friends' relationships. Stafford (2011) argues that the relationship in Facebook is maintained as "user using Facebook, keeping in touch with friends, showing, maintaining or fixing a relationship with friends." Park et al. (2011) [17] argues that the motivations of the relationship are unusual, it can help users build and maintain a weak connection between new friends and classmates on Facebook, not only can they make online interests, but also to understand the new friends offline of information and trends.

In this regard, WeChat is a large online community that users can interact with friends, users can not only send information with friends, but also can be used to make new friends. Members of this community can build friendships through behavioral strategies such as mutual communication, endorsement and self-presentation, and also promote their interests in this community.

\section{B. Self-presentation strategy}

Self-presentation is defined as individual's attempts to put across information about oneself in certain images of other's mind, and establish identity to targeted individuals. Originally self-presentation is the concept of study on interpersonal communication. Later on it is widely applied to the context of online social networks. Related research focuses on discusses the limitations of social communication clues and explores how the process of self-presentation helps to manage relationships. Any message that anyone discloses to others is selfpresentation [7][18]. The breadth and depth of self-presentation grew linearly over time between individuals, thus enhanced the trust between the individuals and promoted the closeness between people. Self-presentation became an important factor in the management of relationships.

Self-presentation entails purposes and motivationaloriented behavior as well. In both context of computermediated-communication or face-to-face, individuals want to build relationships with others, get social support, or get medical kind of supports through self-presentation behavior [2][11]. Studies of self-presentation in online chat rooms indicate that there was a higher degree of self-presentation strategy concerns when the motivations were to seek information other than to connect people who wanted to establish relationships [4]. In general, the motives of WeChat usage should have a considerable degree of impact on the selfpresentation behavior online, and this paper is about to address this aspect.

The study of self-presentation behavior in community media can only confirm that there is a large amount of selfpresentation of information exchange, but it cannot indicate its real impact on the development of interpersonal relationships. Therefore, for the exploration of self-presentation behavior, this study suggests that the impact of different motives in different aspects should be analyzed from a multi-faceted perspective.

\section{Online social capital}

Social capital generally refers to the benefits one may get through his social relationships. It is a broad concept having multiple definitions indifferent fields [5]. Variety of concepts is attached to social capital in different fields. One put it as "the sum of the resources, actual or virtual, that accrue to an individual or a group by virtue of possessing a durable network of more or less institutionalized relationships of mutual acquaintances and recognition."

Social capital researchers found that social capital boosts the psychological well-being, close relationship with neighbors and friends to maintain his/her self-esteem and satisfaction with life. While individuals go online to WeChat kind of social networked sites, WeChat offers the opportunity to develop and increase the weak relationships, deals connections in a convenient and controlled manner in comparison to the offline ways. By application of WeChat usage strategy, WeChat users can accumulate their social capital day by day for the creation of content on WeChat.

\section{HYPOTHESES}

Unlike the self-presentation of linear and reciprocal processes, the user's self-presentation in the social media must be presented in a number of relationships that have different acquaintances before they must try to strike a balance in order to achieve the goal of self, which will affect the development of interpersonal intimacy. There has been a study of selfpresentation in community media that found that users in the non-anonymous community media would exchange information on their own, but they were on the shallow and unconvincing [4]. The WeChat platform is different from the FACEBOOK platform. With a business attribute WeChat usage has a different strategy, thus accumulating a certain degree of social capital.

WeChat can not only serve as a platform to maintain the existing interpersonal relationships, but also to help individuals develop new interests of different social relations. Strategic applications definitely can increase the user's online social capital. Community environment is conducive to the user to expand the new social relations layer, and even link many of the weak extension of the distant stranger relationship. Some scholars believe that individual online behavior via WeChat can maintain existing relationships and somehow develop a larger interpersonal link, build meaningful new social circles, develop a bigger and more heterogeneous personal network, proactively maintain relationships, and interpersonal networks. Based on this argument, this paper argues that social networking sites, here the WeChat, are not only conducive to the maintenance of social capital and the expansion of individual bridging social capital, and through the management of multi-level social relations more conducive to online and offline social resources. So the hypothesis is that:

H1: WeChat user's self-presentation strategy will actively increase the user's online social capital.

On the Internet, users need to be cheerful and optimistic to maintain a positive interaction with friends, and strive to maintain its continuity, but also through the common use of WeChat applications and tasks to promote the growth of 
relations, that is, to create new social relations. Stafford (2011) [17] argues that relationship maintenance can be divided into five dimensions: positivity, assurances, openness, tasks, and networks. According to Park (2011) et al [15], the study of personal behavior management and relational intimacy in Facebook indicated a positive relationship between the motives of usage and the positivity dimension of relationship maintenance. Characters in relationship maintenance like the enthusiasm, openness, etc. are deeply associated with the selfpresentation on WeChat. WeChat users would like to post and express concerning attitude to actively connect with friends.

Therefore, this study suggests that the relationship can be maintained as a user's motive to use WeChat. With clear motives in head, the WeChat users would like to employ behavior strategy to magnify the impact of social connections. The formation of online social capital can be enhanced. Therefore the paper put the hypotheses 2 as below:

$\mathrm{H} 2$ : The motives of usage of WeChat will moderate the impact of self-presentation on the formation of social capital of WeChat users.

The research conceptual model was depicted in Figure I.

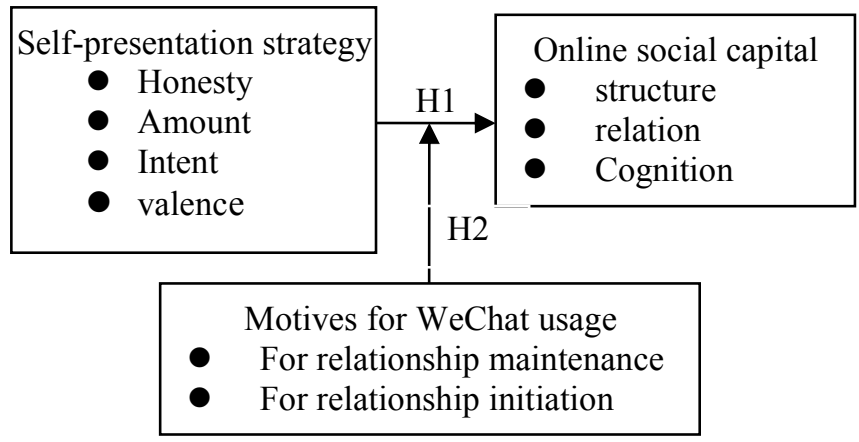

Fig. 1. Research Framework Design

\section{METHOD}

In this study, a questionnaire survey was conducted to investigate WeChat users aged over 18-44 with more than half a year usage during February 26, 2017 and May 31, 2017. After the questionnaire design was completed, it was tested by $20 \mathrm{WeChat}$ users considering the issues such as unambiguity, fluency, simplicity. After the completion of the modification of the test questionnaire, the study was published in the WeChat platform, and the sojump.com as well for interviewee to complete.

For motive measurement, this paper refers to Park (2011) et al [15], and the measurement of online self-presentation refers to Wheeless (1978) [18]. This study divides self-disclosure into four facets of honesty, quantity, purpose, positive $\&$ negative. The measurement of online social capital was referred to Chiu (206) et al [13].

This study will be user age, duration, and education as controllable variables. These variables are often used in studies related to social capital.

As for calculation of online social capital, the paper employs the formula as below:
Online social capital $=$ (the eigenvalue of the relational dimension / the sum of the three eigenvalues) * the factor score of the relation dimension + (the eigenvalue of the structural dimension / the sum of the three eigenvalues) $*$ the factor score of the structural dimension + (the eigenvalue of the cognitive dimension / the sum of the three eigenvalue) $*$ the factor score of the cognitive dimension.

\section{RESULTS}

The survey acquired 202 dataset. With application of SPSS analysis, dataset of self-presentation group, online social capital group and the motives for WeChat usage group got the Cronbach's Alpha as $0.801,0.863$ and 0.823 . The dataset of measurement passed the reliability test and validity test.

First, in order to test the influence of self-presentation on online social capital, this paper takes online social capital (using factor analysis result calculation sequence) as the dependent variable and WeChat usage self-presentation as independent variables, and the age, duration, and education as a control variable to join the regression equation, the analysis results shown in the table I. In the table, model A represents the effect of control variables on online social capital. On the basis of a, we add the independent variables to use the strategy to run the multiple regression to obtain the model $B$, adjust the $R$ square value to 0.189 , the $\mathrm{F}$ value is 0.01 level, the regression model is better to fit the whole, can explain the online society Capital as a whole $18.9 \%$ change, adding WeChat selfpresentation measurements, the model explained the intensity has improved. The regression coefficient is 0.357 and the $p$ value is less than $0.01(\mathrm{sig}=0.000)$. The results show that the microsecond strategy has a significant positive effect on online social capital, that is, $\mathrm{H} 1$ is verified.

Secondly, the paper takes the online social capital as the dependent variable, motive and WeChat self-presentation as an independent variable to conduct regression analysis. The results of the two regressions are shown in Table II. Introducing the control variables we got model $\mathrm{C}$, the $\mathrm{R}$ square is adjusted to 0.612 and the $\mathrm{F}$ value is significant at 0.01 level. In model $\mathrm{D}$, adjust $\mathrm{R}$ square value to $0.621, \mathrm{~F}$ value is significant at 0.01 level. Compared with the models, we can see, $\triangle R 2=0.009, \triangle F=5.647^{*}$, increased the adjustment of the model after the model explained the intensity increased by $0.9 \%$. And the regression coefficient is $0.111, p<0.05$, the regression coefficient is of significance, indicating that the motive of usage of WeChat moderating the impact of selfpresentation on the formation of online social capital on the WeChat platform. Here, $\mathrm{H} 2$ is verified.

TABLE I. SELF-PRESENTATION IMPACT ON SOCIAL CAPITAL MODELS

\begin{tabular}{lllll}
\hline & \multicolumn{2}{c}{ Model A } & \multicolumn{2}{c}{ Model B } \\
\cline { 2 - 4 } & Beta & Sig. & Beta & Sig. \\
\hline
\end{tabular}

Independent variables

\begin{tabular}{lcccc}
\hline Self-presentation & -- & -- & $.357^{* *}$ & .000 \\
\hline Controllable variables & & & & \\
\hline age & $.169^{*}$ & .048 & $.121^{*}$ & .013 \\
\hline
\end{tabular}




\begin{tabular}{lcccc}
\hline duration & .088 & .305 & .078 & .329 \\
\hline education & -.105 & .130 & -.080 & .216 \\
\hline $\mathrm{R}^{2}$ & .091 & .213 \\
\hline Adj. $\mathrm{R}^{2}$ & .068 & .189 \\
\hline $\mathrm{F}$ & $3.956^{* *}$ & $8.832^{* *}$ \\
\hline$\Delta \mathrm{R}^{2}$ & & .122 \\
\hline$\Delta \mathrm{F}$ & & $30.271^{* *}$ \\
\hline
\end{tabular}

TABLE II. MODERATING ROLE OF MOTIVES

\begin{tabular}{lcccc}
\hline & \multicolumn{2}{c}{ Model C } & \multicolumn{2}{c}{ Model D } \\
\cline { 2 - 5 } & Beta & Sig. & Beta & Sig. \\
\hline Independent variables & & & & \\
\hline Self-presentation & $.692^{* *}$ & .000 & $.729^{* *}$ & .000 \\
\hline Motives & $.667^{* *}$ & .000 & $.678^{* *}$ & .000 \\
\hline Controllable variables & & & & \\
\hline Self-presentation*Motives & -- & -- & $.111^{*}$ & .018 \\
\hline Controllable variables & & & & \\
\hline age & & & & \\
\hline duration & .020 & .723 & .041 & .461 \\
\hline education & .086 & .121 & .068 & .219 \\
\hline $\mathrm{R}^{2}$ & -.082 & .070 & -.074 & .097 \\
\hline Adj.R ${ }^{2}$ & & .625 & & .636 \\
\hline $\mathrm{F}$ & & .612 & & .621 \\
\hline$\Delta \mathrm{R}^{2}$ & & & & \\
\hline$\Delta \mathrm{F}$ & & & & \\
\hline
\end{tabular}

\section{CONCLUSION}

WeChat users post personal issues, comment on friends' posts, press like on WeChat, while connecting social ties. For some users, there are weak motives to post and just for memory of some ideas or for fun. Unintentionally, some post draw attentions of certain viewers. Weak ties can be initiated. Social capital of the WeChat user is enhanced for certain extent. If the WeChat users have the motives of maintain and initiation of social relationships, the formation of social capital can be much more effective.

When users deliver contents or express the identity on WeChat, certain behavior strategies can be applied to achieve social capital formation goals. Daily self-presentation on WeChat helps maintain social relationships and initiate new relationships. This paper found if there is a strong purpose to form online social capital, user intends to adapt self-behavior management strategy. The beginning of the relationship with WeChat's business motives and the self-presentation of the various dimensions is to be positive correlation, which is the same to the findings of Park(2011) et al [15].
The self-presentation strategy contributes to the accumulation of online social capital formation. While with the intentions to maintain social relationships and create new relationships, the WeChat users can magnify the formation of online social capital shaped by users' self-presentation on WeChat. The paper found that most of the WeChat users post without a specific strong purpose, and is more kind of accumulation of self-memoir. WeChat offers the function of micro-apps which lead to the business mode of $\mathrm{c} 2 \mathrm{c}$ transactions The higher the social capital one owns the more credit he or she will entails. For the Belt \& Road initiative, WeChat is somehow a way to connect business people, and now is becoming a common tool for their mutual communication. When businessman becomes a WeChat user, he can enhance their credit by accumulation their online social capital via WeChat. With intention to create business relationship or maintain existing relationships, the businessman post daily, which can positively impact the accumulation of the online social capital, and benefit the business.

\section{ACKNOWLEDGMENT}

The authors would like to thank the two anonymous reviewers for their constructive feedback throughout the review process. The authors thank to the support of affiliation institution, Yunnan University of Finance and Economics.

\section{REFERENCES}

[1] R.F. Baumeister, and M.R. Leary, "The need to belong: Desire for interpersonal attachments as a fundamental human motivation," Psychological Bulletin, vol. 117, 1995, pp. 497-529.

[2] S.R. Chaudoir, and D.M. Quinn, "Revealing concealable stigmatized identities: The impact of disclosure motivations and positive firstdisclosure experiences on fear of disclosure and well-being," Journal of Social Issues, vol. 66, 201, pp. 570-584.

[3] C.M. Chiu, M.H. Hsu, and E.T.G. Wang, "Understanding knowledge sharing in virtual communities: An integration of social capital and social cognitive theories," Decision Support Systems, vol. 42, 2006, pp. 1872-1888.

[4] S.H. Cho, "Effects of motivations and gender on adolescents' selfdisclosure in online chatting," Cyber psychology \& Behavior, vol. 10, 2007, pp. 339-345.

[5] J.S. Coleman, "Social capital in the creation of human capital," The American Journal of Sociology, vol. 94, 1988.

[6] C. Chan, "When One App Rules Them All: The Case of WeChat and Mobile in China," Software World. New York, 2015, pp. 529-531.

[7] P.C. Cozby, "Effects of density, activity, and personality on environmental preferences," Journal of Research in Personality, vol. 7, 1973, pp. 45-60.

[8] D.C. DeAndrea, and J.B. Walther, "Attributions for inconsistencies between online and offline self-presentations. Communication Research," vol. 38, 2011, pp. 805-825.

[9] V. Derlega, B. Winstead, P. Wong, and M. Greenspan, "Self-disclosure and relationship development: An attributional analysis," In M. E. Roloff \& G. R. Miller (Eds.), Interpersonal processes: New directions in communication research, Thousand Oaks, CA: Sage, pp. 172-187.

[10] N.B. Ellison, C. Steinfield, and C. Lampe, "The benefits of Facebook "friends": Social capital and college students' use of social online networks," Journal of Computer-Mediated Communication, vol. 11, 2007. 
[11] L. Fletcher-Tomenius \&A. Vossler, "Trust in online therapeutic relationships: The therapist's experience Counselling Psychology Review," 24(2), 2009, pp. 24-34.

[12] S.M. Jourard, "Self-disclosure: An experimental analysis of the transparent self. Oxford," England: John Wiley \& Sons, 1971.

[13] Y. Kim, D. Sohn \& S.M. Choi, "Cultural difference in motivations for using social network sites: A comparative study of American and Korean college students.," Computers in Human Behavior, 27, 2011, pp. $365-372$.

[14] J. Nahapiet \& S. Ghoshal, "Social capital, intellectual capital, and the organizational advantage," Academy of Management Review, 23(2), 1998, pp. 242-266.
[15] N. Park, B. Jin \& S.A. Jin, "Effects of self-disclosure on relational intimacy in Facebook.," Computers in Human Behavior, 27(5), 2011, pp. 1974-1983.

[16] R.M. Ryan \& E.L. Deci, "Self-determination theory and the facilitation of intrinsic motivation, social development, and wellbeing," American Psychologist, 55, 2000, pp. 68-78.

[17] L. Stafford, "Measuring relationship maintenance behaviors: Critique and development of the revised relationship maintenance behavior scale," Journal of Social and Personal Relationships, 28(2), 2011, pp. 278-303,

[18] L.R. Wheeless, "A follow-up study of the relationships among trust, disclosure, and interpersonal solidarity," Human Communication Research, 4(2), 1978, pp. 143-157. 